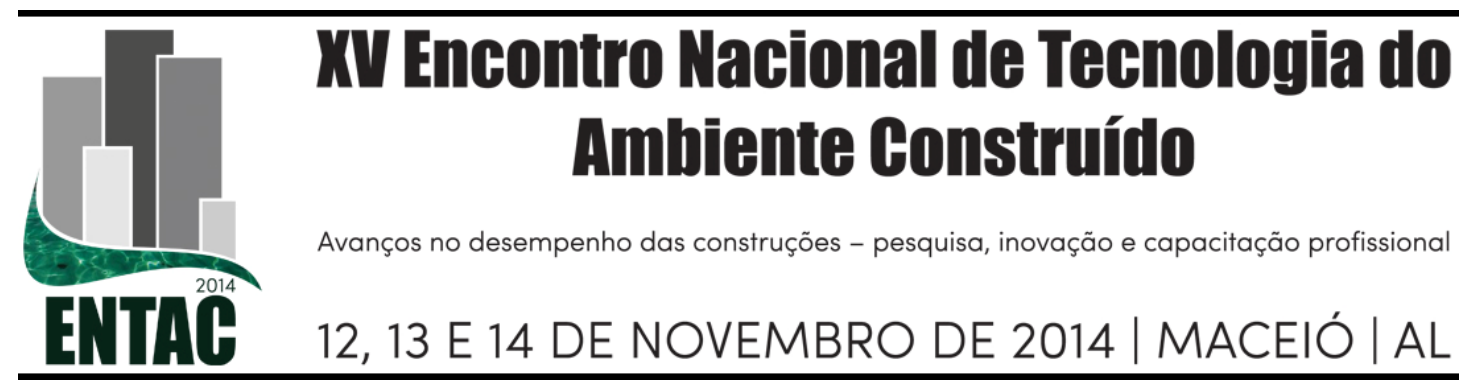

\title{
CARACTERIZAÇÃO DA CONCEPÇÃO DE PROJETOS EM INCORPORADORAS SOB A ÓTICA DA GESTÃO DE RISCOS
}

\author{
BARRETO, Felipe (1); ANDERY, Paulo (2) \\ (1) Pós-graduação em Construção Civil da UFMG, t, e-mail: felipebarreto87@gmail.com (2) \\ Departamento de Engenharia de Materiais e Construção da UFMG , tel. 313409 1856, e-mail: \\ pandery@ufmg.br
}

\begin{abstract}
RESUMO
O presente trabalho tem por objetivo traçar um diagnóstico sobre a gestão de riscos no processo de projeto de empresas incorporadoras de pequeno porte, através da realização de estudo de caso múltiplo. São apresentados resultados parciais da pesquisa. O estudo de caso envolveu entrevistas semiestruturadas, análise de documentação e observações diretas de rotinas de trabalho. Com os dados coletados foi possível identificar características das empresas incorporadoras que interferem na gestão e mitigação dos riscos, tendo como referência a Norma ISO 31000. As empresas de estudo apresentam baixa maturidade em gerenciamento de riscos, sem nenhum tipo de análise formal ou sistematizada, sendo que o nível de aceitação aos riscos é alto. Espera-se que, a partir do diagnóstico realizado seja possível propor, em etapa posterior da pesquisa, um Modelo de Análise de Riscos para Fase de Concepção em Projetos de Incorporação Imobiliária condizente com os contextos internos e externos aos quais tais empresas estão inseridas.
\end{abstract}

Palavras-chave:Gestão de Riscos, Processo de Projeto, ISO 31000

\begin{abstract}
The present study aims at establishing a diagnosis on risk management at the design process of Real Estate companies, focusing risk management concepts and tools. Multiple case study method was used. Partial results of the research are presented. The case study involved semi-structured interviews, documents analysis and direct observations of work procedures. With the collected data it was possible to identify management issues that impact on risk management and mitigation, using ISO31000 as conceptual framework.The results point out that the companies have low risk management maturity, without any kind of formal or systematic analysis, with high level of risks acceptance. It is expected that, based on this diagnosis, it will be possible to set up, in later stage of this research, a model of risk analysis for design stage in real estate development projects consistent with the internal and external contexts of such companies.
\end{abstract}

Keywords: Risk management; design management process; ISO 31000.

\section{INTRODUÇÃO}

Como é sabido, o processo de projeto tem crescido em importância em empresas incorporadoras e construtoras (BROCKMAN, 2012; EMMITT, 2010). Dentro dessa estratégia de melhoria da gestão do processo de projeto, um passo importante que as empresas precisam dar é o de focar o processo de projeto dede o ponto de vista da gestão de riscos, a exemplo de outros segmentos do macro setor da construção, como é o caso de grandes empreendimentos de capital, visando garantir a chamada tríade de ferro - escopo, custo e prazo (CHENG, 2011). 
Essa atitude, que ainda é relativamente nova no mercado, de certa forma é mais fácil de ser tomada em empresas incorporadoras de maior porte, por serem gerencialmente melhor estruturadas. Ainda que isso não seja regra, empresas incorporadoras já consolidadas no mercado e com atuação nacional têm gerencias de projeto ou funções equivalentes, têm um maior ou menor grau de padronização no processo de projeto, possuem modelos de coordenação, o que torna possível implementar mecanismos de identificação, análise e mitigação de riscos, ainda que nem sempre com procedimentos estruturados e formais.

O quadro se altera quando se trata de pequenas empresas incorporadoras / construtoras. Essas empresas têm características que tornam mais difícil o amadurecimento do processo de projeto e, com ele, a gestão de riscos na fase de concepção dos empreendimentos. Entre essas características observa-se (BICALHO, 2009) o fato de seu nicho de mercado ser pouco definido, ou seja, os empreendimentos são vinculados a oportunidades de negócio, sem que aja um planejamento estratégico prévio. Outras características são a escassez de pessoal e a sobrecarga de trabalho de seus proprietários (que atuam como gestores de obras e administradores da empresa, simultaneamente), a ausência de procedimentos gerenciais formais e estruturados, a centralização na tomada de decisões e um processo de projeto pouco estruturado, normalmente sobrepondo-se à realização das obras.

Diante desse quadro, parece ser relevante, do ponto de vista de atender demanda do mercado, identificar como pequenas empresas incorporadoras consideram a questão do risco em seus processos de concepção dos empreendimentos, desde a criação de um possível empreendimento até o início das atividades nos canteiros, ou seja, na fase de concepção. Do ponto de vista acadêmico, poucos trabalhos no Brasil têm concentrado sua atenção na análise de mecanismos de gestão de riscos no processo de projeto, e mais ainda em pequenas empresas.

Nesse contexto, o presente trabalho apresenta a primeira etapa de um estudo exploratório e diagnóstico sobre a gestão de riscos no processo de projeto de empresas incorporadoras de pequeno porte. Como referencial básico, para identificação de estratégias de gestão de riscos, é utilizada a Norma ISO 31000.

\section{REVISÃO BIBLIOGRÁFICA}

De acordo com MANSO e MITIDIERI FILHO (2007), o fluxo de desenvolvimento de projeto de um empreendimento imobiliário passa pelas seguintes etapas principais: a) Planejamento estratégico; b) Análise dos terrenos; c) Definição do produto/ Definição das diretrizes para desenvolvimento do projeto; d) Definição dos recursos/ contratação dos projetistas; e) Planejamento e controle do desenvolvimento do projeto; f) Gestão do escopo/ desenvolvimento do projeto; g) Recebimento, análise crítica e validação do projeto; h) Avaliação/ retroalimentação do sistema; i) Validação do projeto; j) Apresentação à equipe de obra; h) Acompanhamento da utilização. No entanto, essas etapas raramente estão presentes no processo de projeto de empresas de pequeno porte (BICALHO, 2009).

Os mecanismos de decisão quanto à realização do empreendimento são normalmente pautados por parâmetros financeiros (ROCHA LIMA JR, 2004). Mesmo sendo uma análise necessária e de grande impacto para a decisão de empreender ou não, deixa lacunas não preenchidas, pois não leva em conta diversas variáveis com grande influência no resultado final do empreendimento. Estas variáveis são, por exemplo, a qualidade dos materiais empregados, grau de inovação das tecnologias adotadas, 
experiência da equipe em projetos similares, estrutura organizacional da companhia, nível de maturidade da companhia com relação à gestão de projetos, lições aprendidas, qualidade do projeto, análises de construtibilidade (integração e compatibilização dos conceitos de projeto e obra), etc.

Portanto, se faz necessária uma análise holística da situação para que a qualidade das decisões tomadas seja a melhor possível considerando o nível de desenvolvimento do projeto e consequentemente o grau de dados e informações disponíveis. A aplicação correta da gestão de riscos e o enquadramento de teorias, hoje aplicáveis apenas em megaprojetos, ao contexto interno e externo das empresas objeto de estudo pode ser um caminho mais suave e menos desgastante para se alcançar o sucesso dos projetos, ou seja, executar e receber o que foi planejado respeitando as restrições de custo, escopo, tempo e qualidade.

O processo de concepção de empreendimentos é um ciclo iterativo de amadurecimento e maturação de ideias, conceitos e definições. $\mathrm{O}$ que se procura durante este ciclo é a redução das incertezas e das indefinições que afetam os objetivos previstos para implantação do projeto.

Incertezas são definidas como um estado, mesmo que parcial, de deficiência de informação relacionada ao entendimento ou conhecimento de um evento, suas consequências ou probabilidade de ocorrência (ISO 31.000, 2009).

Nesse contexto, uma abordagem menos onerosa ao projeto é a abordagem proativa, voltada não a solução de problemas, mas à análise prévia de falhas potenciais. Neste caso, procura-se identificar e avaliar os principais riscos, suas respectivas causas e consequências a que o empreendimento estará sujeito durante as diferentes fases de desenvolvimento.

A ISO 31.000 define risco como o efeito das incertezas sobre os objetivos do projeto. Desta forma, através de uma ampla identificação, uma avaliação realística e um controle efetivo dos riscos do projeto pode-se alcançar um nível de incerteza aceitável e condizente com a capacidade dos patrocinadores do projeto em conviver com riscos. Já a NASA (2009) define risco como uma medida de uma potencial inabilidade em atingir os objetivos pré-definidos do projeto.

São definidos 7 processos de gerenciamento de riscos pela ISO 31.000, a saber: Estabelecer o Contexto; Identificar os Riscos; Analisar os Riscos; Avaliar os Riscos; Desenvolver Planos de Tratamento; Comunicar e Consultar os Riscos; Monitorar e Revisar os Riscos. Estes processos são empregados durante o ciclo de vida do projeto, visando garantir a redução dos impactos negativos e a catalisação dos impactos positivos nos objetivos do projeto.

A análise detalhada dos riscos durante a fase de concepção de empreendimentos, segundo a ISO 31000, traz como benefícios a criação e proteção de valor para os agentes envolvidos e, logicamente, o aumento da probabilidade de serem alcançados os indicadores de desempenho objetivados, entre outros benefícios (ISO 31000, 2009).

Estes benefícios podem ser incorporados ao processo de concepção de empreendimentos imobiliários partindo da definição de um processo formal de análise e classificação do nível de incerteza que o projeto apresenta, ou seja, um processo formal de gerenciamento de riscos.

As metodologias FEL (Front End Loading) e PDRI (Project Definition Ratio Index), utilizadas amplamente nos megaprojetos, são também uma forma de se definir o grau de 
incerteza dos projetos. Estas procuram definir, através de uma análise de maturidade e de benchmarking, as chances que o projeto possui de ser um sucesso. Mesmo sendo rara sua aplicação em projetos de menor porte, o conceito de validação pode ser transposto para o cenário das empresas construtoras-incorporadoras.

Por se tratar de projetos de pequeno/médio porte, estão sujeitos a maiores desafios do que projetos de grande porte, devido principalmente a sua característica inata de restrição de recursos, cronograma desafiador, grande competição e baixas margem de lucro (SMITH E BOHN, 1999). Para TAROUN (2014), nenhum projeto de construção é livre de riscos, estes podem ser gerenciados, porém nunca ignorados. Estas constatações corroboram com a evidente necessidade de uma gestão cuidadosa dos riscos.

\section{METODOLOGIA}

Foi escolhido como estratégia de pesquisa o Estudo de Caso Prospectivo ou Exploratório (YIN, 2010). O tipo de estudo de caso adotado para este trabalho foi o estudo de casos múltiplos, onde foram realizados três estudos de casos em empresas de médio/pequeno porte que incorporam/constroem empreendimentos residenciais na região metropolitana de Belo Horizonte/MG e na Região de Campos dos Goytacazes/RJ.

O desenvolvimento do estudo de caso foi estruturado nas fases de: planejamento, elaboração de protocolo de estudo de caso detalhado, elaboração do questionário e lista de documentos a serem consultados, identificação das potenciais empresas e realização dos estudos de caso. Os estudos de caso foram desenvolvidos fazendo uso de três fontes principais de evidência: entrevistas semiestruturadas, observação direta e análise da documentação. As entrevistas semiestruturadas foram realizadas a partir da escolha prévia dos profissionais, considerando fatores como experiência, capacitação técnica e posição no organograma da companhia.

Foram analisados, durante o desenvolvimento dos casos, os seguintes documentos principais: Procedimentos do Sistema da Gestão da Qualidade (SGQ) relacionados a incorporação imobiliária - aferir se são ou não realmente utilizados; Procedimentos para análise de viabilidade dos empreendimentos; Procedimentos e documentos utilizados no processo de projeto (design); Projetos e maquetes eletrônicas - visando analisar se é previsto no projeto algum tipo de análise de compatibilização; Procedimentos de planejamento e orçamentação - visando aferir se são ou não realmente utilizados;Programa do empreendimento - documentação descrevendo escopo, premissas e restrições e manuais dos softwares de incorporação, orçamentação, planejamento e controle utilizados pelas empresas.

\section{ESTUDO DE CASO: ANÁLISE DE RISCOS NO PROCESSO DE PROJETO}

\subsection{Caracterização das empresas}

Para caracterização do processo de concepção de empreendimentos foram escolhidas três empresas que atenderam aos parâmetros de seleção adotados no planejamento do estudo de caso. A caracterização foi realizada seguindo fielmente a metodologia definida na seção 3 deste artigo.

O questionário de estudo de caso contempla os seguintes temas principais:

- Geral: Perfil do Entrevistado; Perfil da Empresa; 
- Processo de concepção de empreendimentos: A ideia original; O processo de Projeto; Planejamento e Controle de Prazo; Orçamentação e Controle de Custos; Construtibilidade.

Os questionários foram aplicados uma única vez em cada empresa. Os escolhidos para as entrevistas eram sócios e diretores de incorporação e engenharia. Cada entrevista durou cerca de 3 horas.

As três empresas selecionadas são construtoras e incorporadoras, responsáveis por todo o ciclo de vida do empreendimento. A partir dos dados coletados no questionário foi possível a construção de uma tabela comparativa do perfil das empresas objeto de estudo, conforme tabela 1 abaixo.

Tabela 1 - Perfil das Empresas Pesquisadas

\begin{tabular}{l|c|c|c}
\cline { 2 - 4 } & Empresa A & Empresa B & Empresa C \\
\hline Local atuação & Belo Horizonte & Belo Horizonte & Campos dos Goytacazes \\
\hline Funcionários & 450 & 160 & 400 \\
\hline Mercado Atuação & Edifícios Habitacionais & $\begin{array}{c}\text { Edifícios Habitacionais / } \\
\text { Comerciais }\end{array}$ & $\begin{array}{c}\text { Edifícios Habitacionais / } \\
\text { Comerciais }\end{array}$ \\
\hline Tipologia Média do Produto & $\begin{array}{c}\text { Apartamento 2 } \\
\text { dormitórios }\end{array}$ & $\begin{array}{c}\text { Não existe tipologia } \\
\text { específica }\end{array}$ & $\begin{array}{c}\text { Apartamento } 3 \\
\text { dormitórios }\end{array}$ \\
\hline Número de Empreendimentos Lançados & 10 & 12 & 11 \\
\hline Número de unidades incorporadas & 1581 & 450 & 340 \\
\hline Padrão Construtivo & Baixo & Normal & Normal \\
\hline Sistema de Gestão & ISO 9001 e PBQP-H & ISO 9001 e PBQP-H & Não possui \\
\hline
\end{tabular}

Para além do que pode ser identificado na tabela anterior, foi possível observar outras características importantes durante o desenvolvimento dos casos. A empresa A, mesmo possuindo um número de empreendimentos muito similar às demais, apresenta uma estrutura organizacional melhor estruturada, com processos, responsabilidades, procedimentos bem definidos. Esta possui três linhas pré-estabelecidas de empreendimentos. O processo de identificação de terrenos parte da premissa que é necessário encontrar um terreno que se adeque a um dos três produtos padrões. Para isso, a empresa faz prospecção constante de potenciais terrenos armazenando-os em uma base de dados. A empresa possui uma boa fundamentação para análise de viabilidade fazendo análise de VPL (Valor Presente Líquido) e TIR (Taxa Interna de Retorno). O estudo de viabilidade é dividido em duas fases: Viabilidade do Terreno e Viabilidade do Lançamento. O desenvolvimento dos projetos é divido em 4 fases. A primeira fase corresponde à concepção do empreendimento. Foi identificado que as demais fases (implantação do empreendimento) possuem melhores processos e ferramentas de controle. A empresa entende que muitos erros e retrabalhos ocorridos durante a implantação se devem a uma fraca gestão da fase ouro.

A empresa B se encontra em fase transitória, partindo de uma empresa informal para uma empresa que possui cada vez mais procedimentos e processos formalizados. No entanto, ainda carece de processos que auxiliem a tomada de decisão e o controle efetivo das atividades em desenvolvimento. O cronograma e o orçamento elaborados não contemplam a fase de concepção.

A última empresa analisada está localizada no município de Campos dos Goytacazes/RJ. Diferentemente das demais esta não possui certificação ISO ou PBQP$\mathrm{H}$ e por isso não possui processos formais de gestão da fase de concepção. A omissão quanto a este tipo de certificação se deve ao mercado da região não exigir tais 
certificações e a empresa utilizar de recursos próprios para implantação da maior parte dos seus empreendimentos.

\subsection{Caracterização das etapas iniciais dos empreendimentos}

Mesmo apresentando pontos convergentes, cada empresa possui um fluxo do processo de concepção diferenciado. $\mathrm{Na}$ empresa $\mathrm{A}$, empresa de maior porte dentre as três pesquisadas, a fase 1 - prospecção de terrenos é feita de forma cuidadosa, onde o empreendedor busca um terreno que se adeque a um dos seus três produtos padronizados. A empresa possui um banco de dados extenso e detalhado com todos os terrenos já prospectados, permitindo a escolha da opção que proporcione maior rentabilidade e menor impacto no projeto original. A fase 2 - viabilidade do terreno é executada após um pré-contrato assinado com o dono do terreno. Neste momento é feito, estudo de viabilidade econômica (com base em índices), projeto conceitual, levantamento topográfico, ensaios do solo, estudo de massa e análise jurídica. Sendo identificada a viabilidade o empreendimento é aprovado pela diretoria da empresa e um contrato de permuta é assinado. É elaborado o projeto legal e este submetido à aprovação da prefeitura (fase 3). Na fase 4 - viabilidade de lançamento, é elaborado um pré-orçamento, onde são considerados quantitativos reais do empreendimento, porém ainda com um certo grau de incerteza devido à falta dos projetos executivos. Neste momento, o projeto passa por uma última aprovação da diretoria, sendo ainda possível a dissolução do contrato de permuta. A fase 5 contempla a incorporação e lançamento do empreendimento e o início das vendas. Apenas na fase 6 são elaborados os projetos executivos para então se obter o orçamento e cronograma final da obra. Os projetos executivos são elaborados por empresas parceiras, sendo que há uma redução de cerca de $60 \%$ nos custos nesta etapa, dada a padronização e repetitividade dos projetos. Portanto, ao final da fase 6, é feita a entrega a equipe de obra de um "pacote de informações", contemplando todos os projetos executivos, o cronograma de implantação e o orçamento base. Na figura 1 é apresentado o processo de concepção adotado pela empresa A.

\section{Figura 1 - Processo de Concepção dos Empreendimentos - Empresa A}

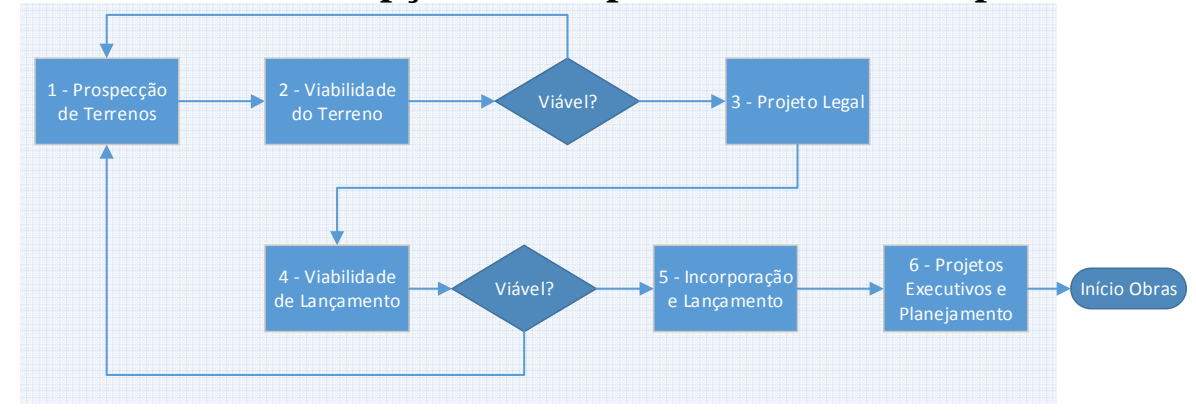

A empresa B recebe constantemente ofertas de terrenos por meio de imobiliárias parceiras. Caso algum destes terrenos se encaixe no perfil desejado pela empresa é feita uma Análise de Viabilidade do Terreno. Esta análise de viabilidade consiste basicamente de um estudo comparativo entre o custo médio por metro quadrado (dados históricos) e o valor venal por metro quadrado esperado (pesquisa de mercado). A empresa adota uma contingência de $20 \%$ no valor venal e aprova o projeto se alcançar uma margem de lucro mínima de 30\%. Esta análise simples habilita a assinatura do contrato de permuta e o desenvolvimento do projeto legal. Não são consideradas fontes importantes de incerteza, como as características do solo e viabilidade jurídica. Ainda durante a fase 2 a empresa elabora um projeto conceitual e o escopo base do 
empreendimento, o qual é parte componente do contrato de permuta. Com o projeto legal aprovado o empreendimento é incorporado e lançado (fase 3). Por fim, são feitos os projetos executivos (empresas subcontratadas parceiras) e o orçamento/cronograma (consultoria externa especializada). Todos os projetos executivos são elaborados antes do início das obras. A figura 2 apresenta o processo da empresa B.

Figura 2 - Processo de Concepção dos Empreendimentos - Empresa B

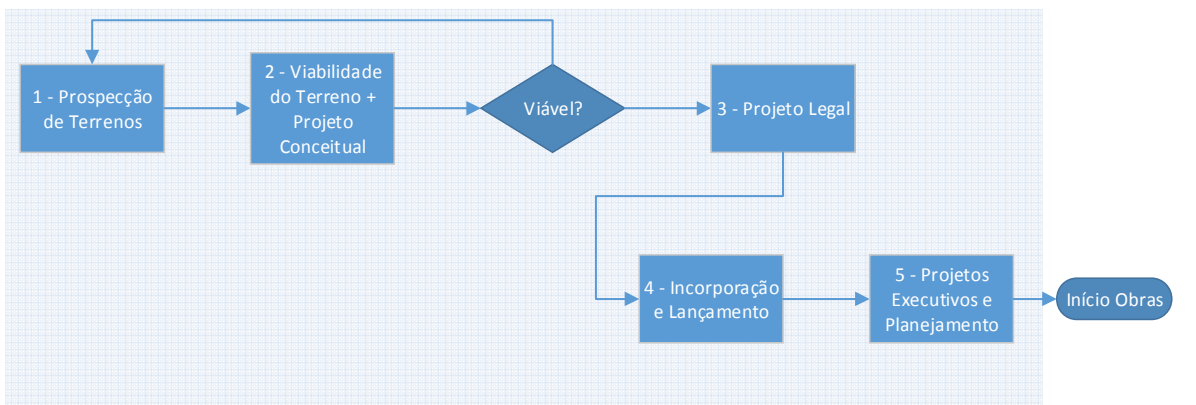

A empresa $\mathrm{C}$ realiza uma prospecção de terrenos que se adequem à tipologia do produto que pretende construir. $\mathrm{Na}$ fase 2 é realizada a análise de viabilidade do terreno de forma similar à adotada pela empresa $\mathrm{B}$, não sendo considerados na tomada de decisão os cálculos de VPL e TIR. Após aprovação do empreendimento, decide-se se o terreno será permutado ou adquirido. Logo após a aprovação do projeto legal a empresa inicia a elaboração dos projetos executivos. Há uma grande preocupação interna em lançar o produto apenas após ter os projetos executivos auxiliares prontos. Isto porque a empresa deseja entregar um produto $100 \%$ fiel àquele apresentado no material de lançamento. Mesmo sendo a única empresa que não possui certificação de qualidade, e evidente o cuidado em entregar aos seus clientes um produto fiel ao vendido e que respeita as normas técnicas. A empresa preza por sua imagem e reputação. Há também uma participação ativa da equipe de obras no desenvolvimento dos projetos desde a fase conceitual. Isto se dá devido, principalmente, ao fato de que os projetos arquitetônicos e estruturais são elaborados internamente.

\section{Figura 3 - Processo de Concepção dos Empreendimentos - Empresa C}

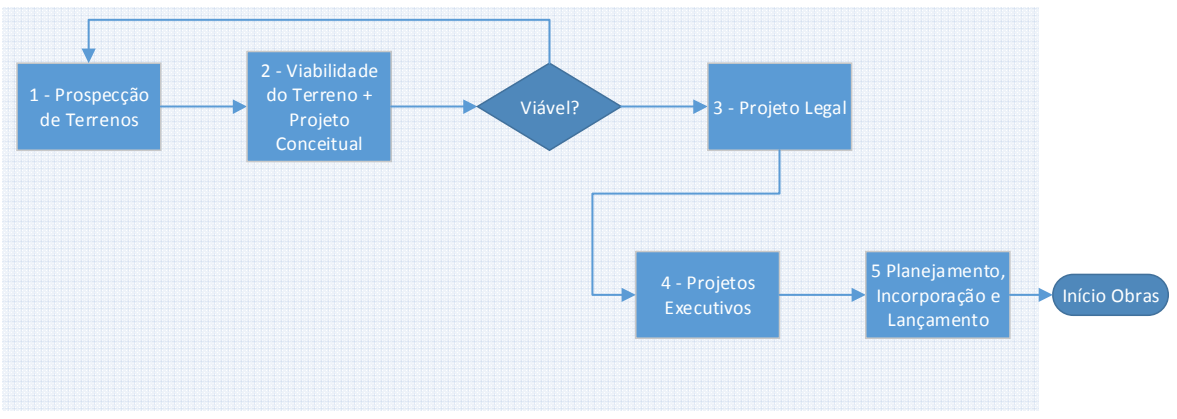

Os três modelos apresentados anteriormente se aproximam do modelo proposto por ROMANO (2006), no qual o processo de projeto é decomposto em três macrofases: Pré-projetação; Projetação; Pós-projetação. No entanto, nas três empresas foi observada uma baixa preocupação e detalhamento da fase de pré-projetação. Nos três casos estudados, o planejamento e os procedimentos elaborados são em sua grande maioria voltados para a fase de execução das obras. Há, portanto, um baixo controle e pouca preocupação com o planejamento e controle da fase de concepção. 
Nenhuma das empresas objeto de estudo possui um processo ou procedimento formal de gerenciamento de riscos. Esta característica já era esperada, devido ao porte das empresas, recursos limitados e a cultura pouco formal das empresas construtorasincorporadoras brasileiras.

A redução do grau de incerteza significa uma maior maturidade do projeto e um maior nível de informações disponíveis para sua implantação. Uma melhor definição do produto e da forma como este produto será implantado, aprimora a capacidade do gerente do projeto em prever uma série de problemas tão usuais nos empreendimentos imobiliários. Mesmo com a consciência de que a fase de concepção é fundamental para o sucesso final do projeto, é dado, pelas empresas, pouco ou menor valor ao seu desenvolvimento.

Foram identificados, para cada fase do processo de concepção, elementos que contribuem de alguma forma para a redução das incertezas do projeto $\mathrm{e}$ consequentemente para o gerenciamento de riscos. Para cada um dos elementos identificados foi feita uma correlação com um dos 7 processos da ISO31000 anteriormente. Esta análise é mostrada na tabela 2 a seguir.

Tabela 2 - Elementos de Gestão de Riscos X ISO 31000

\begin{tabular}{|c|c|c|c|c|c|c|}
\hline Fase do Processo Concepção & Elementos de Gestão de Riscos & $\begin{array}{c}\text { Empre } \\
\text { saA }\end{array}$ & \begin{tabular}{|c|} 
Empresa \\
B
\end{tabular} & $\begin{array}{c}\text { Empresa } \\
\mathrm{C}\end{array}$ & Processos ISO 31.000 & Considerações \\
\hline \multirow{2}{*}{ Prospeção de Terrenos } & $\begin{array}{l}\text { Identificação dos melhores terrenos que } \\
\text { se adequem ao produto desejado empresa }\end{array}$ & Q & (1) & (1) & \multirow[t]{2}{*}{$\begin{array}{l}=>\text { Estabelecer o Contexto } \\
\Rightarrow>\text { Identificar os Riscos } \\
\Rightarrow>\text { Comunicar e Consultar } \\
\text { os Riscos }\end{array}$} & \multirow{2}{*}{$\begin{array}{l}\text { Nesta fase é estabelecido o contexto ao } \\
\text { qual o projeto está sujeito, tanto interno, } \\
\text { organizacional, quanto externo, } \\
\text { comunidade, proprietário do terreno, } \\
\text { legais e regulatórios, etc. Além disso, já } \\
\text { são identificados diversos riscos que } \\
\text { podem afetar o projeto. Também são } \\
\text { utilizadas as lições aprendidas para } \\
\text { aprimorar a escolha dos melhores terrenos }\end{array}$} \\
\hline & $\begin{array}{l}\text { Construção de banco de dados com todos } \\
\text { os terrenos já propectados }\end{array}$ & $\theta$ & (2) & (2) & & \\
\hline \multirow{5}{*}{ Viabilidade do Terreno } & Estudos iniciais do terreno & $\theta$ & (2) & $\theta$ & \multirow{5}{*}{$\begin{array}{l}=>\text { Identificar os Riscos } \\
\Rightarrow>\text { Analisar os Riscos } \\
\Rightarrow \text { Avaliar os Riscos } \\
\Rightarrow>\text { Tratar os Riscos }\end{array}$} & \multirow{5}{*}{$\begin{array}{l}\text { A viabilidade do terreno é composta por } \\
\text { uma série de estudos e levantamentos de } \\
\text { informações que visam reduzir o nível de } \\
\text { incerteza do projeto. O projeto conceitual } \\
\text { já prevê algumas medidas de tratamento } \\
\text { dos riscos. }\end{array}$} \\
\hline & Análise de Mercado & 8 & 8 & ( ) & & \\
\hline & Projeto Conceitual & $\theta$ & 8 & 8 & & \\
\hline & \begin{tabular}{|l|} 
Cálculo do VPL e TIR (Análise \\
Econômica)
\end{tabular} & ( ) & (2) & (2) & & \\
\hline & Viabilidade Jurídica & $\theta$ & (2) & $\theta$ & & \\
\hline Projeto Legal & Definição do escopo geral do produto & $\theta$ & $\theta$ & $\theta$ & \begin{tabular}{|l|}
$\Rightarrow>$ Tratar os Riscos \\
$\Rightarrow>$ Monitorar e Revisar os \\
Riscos \\
$\Rightarrow>$ Comunicar e consultar \\
os riscos
\end{tabular} & $\begin{array}{l}\text { O avanço no detalhamento do projeto dá } \\
\text { continuidade ao processo de tratamento } \\
\text { dos riscos já identificados. Exigências da } \\
\text { prefeitura ou mesmo e o novo grau de } \\
\text { informações disponíveis trazem a } \\
\text { necessidade de realizar o monitoramento e } \\
\text { revisão dos riscos. São utilizadas as lições } \\
\text { aprendidas para melhor definição do } \\
\text { produto. }\end{array}$ \\
\hline \multirow{2}{*}{$\begin{array}{l}\text { Viabilidade de Lançamento (somente } \\
\text { empresa A) }\end{array}$} & Elaboração de um pré-orçamento & 8 & (2) & (2) & \multirow[t]{2}{*}{$\begin{array}{l}\Rightarrow>\text { Identificar os Riscos } \\
\Rightarrow>\text { Analisar os Riscos } \\
\Rightarrow>\text { Avaliar os Riscos } \\
\Rightarrow \text { Tratar os Riscos }\end{array}$} & \multirow{2}{*}{$\begin{array}{l}\text { Aborda os mesmos processos da } \\
\text { viabilidade do terreno, porém com maior } \\
\text { nível de detalhe e confiança. Não possui a } \\
\text { importância para decisão de incorporar da } \\
\text { VT, porém pode ser decidido não } \\
\text { implantar o terreno após esta segunda } \\
\text { análise. }\end{array}$} \\
\hline & Revisão da Análise Econômica & 8 & (2) & (2) & & \\
\hline Incorporação e Lançamento & - & - & - & - & - & $\begin{array}{l}\text { Esta etapa gera novos riscos que devem } \\
\text { ser analisados durante o planejamento do } \\
\text { empreendimento e a finalização dos } \\
\text { projetos executivos. }\end{array}$ \\
\hline Fase do Processo Concepção & Elementos de Gestão de Riscos & $\begin{array}{c}\text { Empre } \\
\text { saA }\end{array}$ & \begin{tabular}{|c|} 
Empresa \\
B
\end{tabular} & $\begin{array}{c}\text { Empresa } \\
\mathrm{C}\end{array}$ & Processos ISO 31.000 & Considerações \\
\hline \multirow[b]{2}{*}{ Projetos Executivos e Planejamento } & Detalhamento do escopo & $\theta$ & $\theta$ & $\theta$ & $\begin{array}{l}\Rightarrow>\text { Tratar os Riscos } \\
\Rightarrow>\text { Monitorar e Revisar os } \\
\text { Riscos } \\
\Rightarrow>\text { Comunicar e consultar } \\
\text { os riscos }\end{array}$ & $\begin{array}{l}\text { Riscos identificados são tratados através } \\
\text { da evolução no densenvolvimento do } \\
\text { projeto e a redução do grau de incerteza. }\end{array}$ \\
\hline & Definição do Orçamento & 0 & 0 & 0 & $\begin{array}{l}\Rightarrow>\text { Identificar os Riscos } \\
\Rightarrow>\text { Tratar os Riscos }\end{array}$ & $\begin{array}{l}\text { São identificados riscos relacionados à } \\
\text { baixa definição de projeto ou pouca } \\
\text { confiabilidade nos preços coletados. } \\
\text { Medidas de tratamento podem requerer } \\
\text { melhor detalhe do projeto ou uma pesquisa } \\
\text { de preços mais elaborada e realista. }\end{array}$ \\
\hline
\end{tabular}


Tabela 2 - Elementos de Gestão de Riscos X ISO 31000 (Continuação)

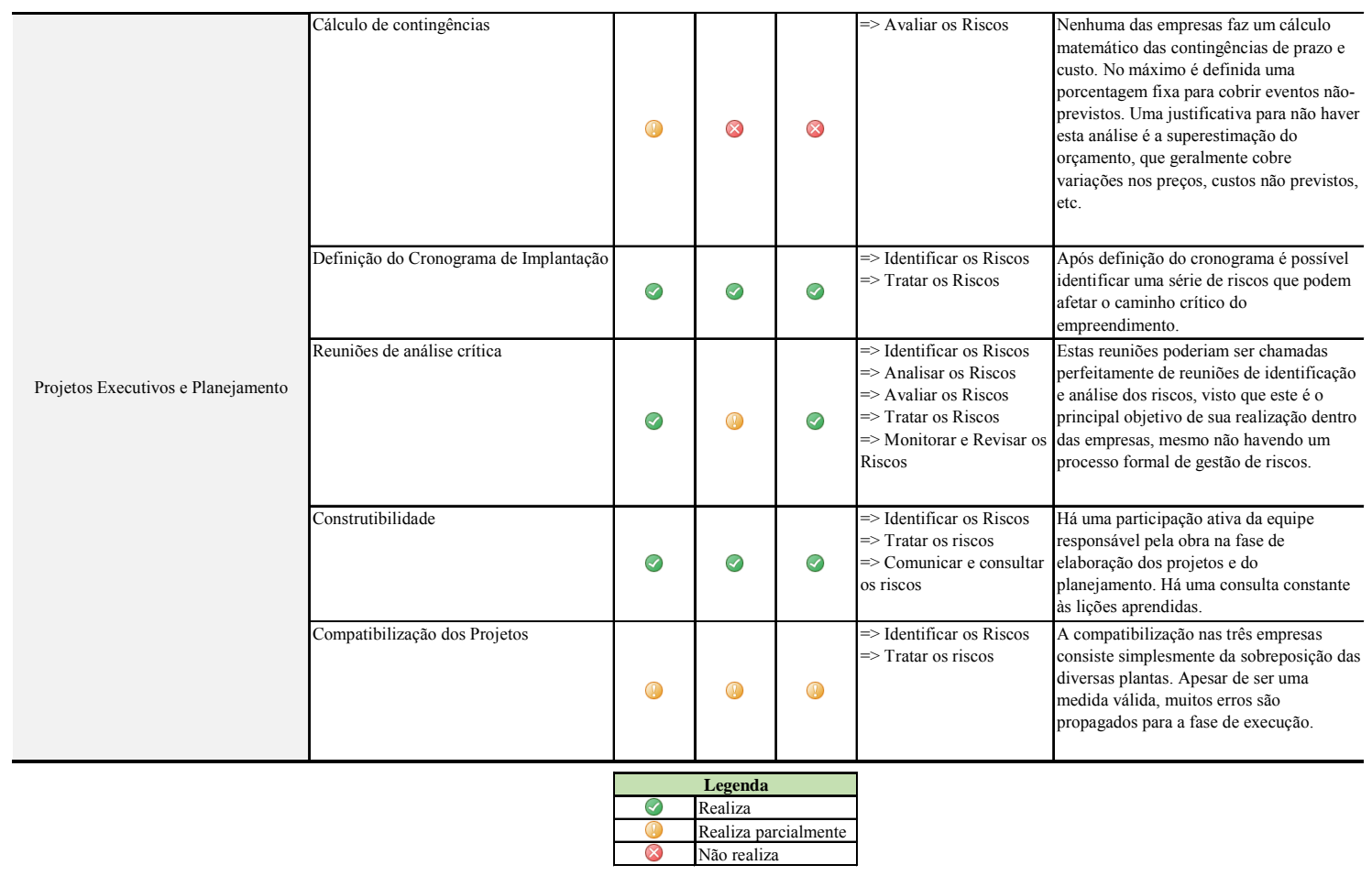

Considerando a tabela 2, e comparando com o observado durante os estudos de caso, empresas que implementam ou possuem ferramentas diretas ou indiretas que visam gerenciar e reduzir os riscos dos seus projetos tendem a ser empresas melhores preparadas, enfrentando cada vez menos surpresas, isto porque sabem medir seus erros e acertos e com esta informação, prever, cada vez melhor como os seus projetos se comportarão no futuro.

Mesmo tendo sido analisados os 9 itens apresentados na tabela, qualquer ferramenta, técnica ou processo que a empresa utilize afim de reduzir as incertezas inerentes aos seus projetos é caracterizado como parte de um trabalho de gerenciamento de riscos, portanto, o gerenciamento de riscos não pode ser visto como algo distante e longe da realidade das empresas, mas sim como uma prática necessária e muitas vezes já aplicada no dia a dia.

\section{CONCLUSÕES}

Mesmo não apresentando uma estrutura formalizada de gerenciamento de riscos, as empresas construtoras-incorporadoras pesquisadas possuem em seu processo de concepção dos empreendimentos uma série de elementos que auxiliam na redução do nível de incerteza. Considerando que as incertezas são fontes de riscos, quanto menor o nível de incerteza do projeto menor o grau de risco que este estará sujeito.

Os elementos de gestão de riscos foram comparados, em uma análise inicial, com os processos da ISO 31.000, evidenciando que a possibilidade de elaboração de um roteiro de concepção de empreendimentos voltado para a redução do grau de riscos. Este tipo de abordagem já é aplicada em projetos de capital através das metodologias FEL e PDRI. Ambas as abordagens procuram definir um pacote de informações padrão mínimo que assista na decisão de aprovar ou não o empreendimento. 
Foi identificado que, de forma geral, as empresas não possuem uma gestão cuidadosa da fase de concepção. Não há um controle de progresso das atividades, não há um cronograma detalhado das atividades. Apenas uma das empresas estudadas desenvolve a análise de viabilidade baseando-se em parâmetros econômicos. Os procedimentos para controle de qualidade são realizados principalmente para manutenção das certificações ISO 9001 e PBQP-H.

Fica evidente, portanto, a necessidade de maior formalidade e padronização na fase de concepção. A utilização de um roteiro estruturado para a fase de concepção, com foco no gerenciamento de riscos, pode trazer melhores resultados globais aos empreendimentos. Este modelo será desenvolvido em etapa posterior da pesquisa.

\section{REFERÊNCIAS}

BICALHO, F. Sistema de Gestão da Qualidade para Empresas Construtoras de Pequeno Porte. (Dissertação). Programa de Pós-graduação em Construção Civil da Universidade Federal de Minas Gerais, 2009.

BROCKMAN, C. Evaluating Construction Project Complexity .In: CIB JOINT INTERNATIONAL SMPOSIUM, Rotterdam, 2012. Proceedings... Rotterdam: CIB, 2012, v. 1, p. 716-727.

CHENG, Y. An exploration into cost influencing factors on construction projects. International Journal of Project Management, 2013, 11 p.

EMMIT, S. Design Management in Architecture, Engineering and Construction: origins and trends. Revista Gestão \& Tecnologia de Projetos,vol. 5, no. 3. 2010.

INTERNATIONAL ORGANIZATION FOR STANDARZATION. ISO 31000:2009. Risk Management Guidelines for development and implementation of risk management. Geneva, Switzerland: International Organization for Standarzation, 2009.

MANSO e MITIDIERI FILHO. Modelo de Sistema de Gestão e Coordenação de Projetos para Empresas Construtoras e Incorporadoras. In: Revista Gestão \& Tecnologia de Projetos, vol. 2, no. 7. 2007.

NATIONAL AERONAUTICS AND SPACE ADMINISTRATION. Guidelines for risk management. Washington, D.C. USA: National Aeronautics and Space Administration (NASA), 2009.

ROCHA LIMA JR. J. Decisão e Planejamento: Fundamentos para a Empresa e Empreendimentos na Construção Civil. Boletim Técnico, Departamento de Engenharia de Construção Civil, Universidade de São Paulo. Disponível em $<$ http://www.pcc.usp.br/files/text/publications/TT_00025.pdf $>$. Acesso em 15.05.2014.

ROMANO, F. Modelo de Referência para o Gerenciamento do Processo de Projeto Integrado de Edificações. In: Revista Gestão \& Tecnologia de Projetos, vol. 1, no. 1, 2006.

SMITH, G.R., BOHN, C.M. Small to medium contractor contingency and assumption of risk. Journal of Construction Engineering Management. 125 (2), 101-109, 1999.

TAROUN, A. Towards a better modeling and assessment of construction risk: Insights froam a literature review. International Journal of Project Management, 2014.

YIN, R. K.Estudo de Caso: Planejamento e Métodos. 4ª Ed. São Paulo: Buckman, 2010. 